Article

\title{
Incidence of the Flipped Classroom in the Physical Education Students' Academic Performance in University Contexts
}

\author{
Francisco Javier Hinojo-Lucena, Ángel Custodio Mingorance-Estrada ${ }^{(\mathbb{B},}$ \\ Juan Manuel Trujillo-Torres * (1) Inmaculada Aznar-Díaz ${ }^{\mathbb{D}}$ and María Pilar Cáceres Reche ${ }^{\mathbb{( D}}$ \\ Department of Didactics and School Organization, University of Granada, 18071 Granada, Spain; \\ fhinojo@ugr.es (F.J.H.-L.); amingoe@ugr.es (Á.C.M.-E.); iaznar@ugr.es (I.A.-D.); caceres@ugr.es (M.P.C.R.) \\ * Correspondence: jttorres@ugr.es; Tel.: +34-609-135-611
}

Received: 19 February 2018; Accepted: 16 April 2018; Published: 25 April 2018

\begin{abstract}
This research analyzed Physical Education students' degree of academic performance with the incorporation of active methodologies, specifically flipped classroom mixed learning, restricted to evaluation periods in the months of June and September. The study focused on whether there are significant differences in this variable through the scores obtained. Through a simple random sampling, 131 students participated in this empiric-analytic research, using an ex-post-facto study with a retrospective design with quasi-control group. A robust test of averages comparison, multiple linear regressions and an evaluation of the relative importance of predictors was conducted. The results show how flipped classroom methodology linearly and positively influences academic performance and correlational motivation and support. As main conclusion, in a hybrid and digitalized learning context, the value of the consideration of active methodologies (flipped classroom) based on emerging pedagogies, allows improving students' achievement and competence development, providing critical, significant, ubiquitous, transformational and especially motivating experiences.
\end{abstract}

Keywords: flipped classroom; methodological change; ICT

\section{Introduction}

The gap between practice in classrooms and training education in Higher Education requires a transformation of the academic model. This new paradigm includes a shift to hybrid learning with the integration of new tools and methodologies that challenges the educational position of the traditional teaching that has existed for decades at universities for the improvement of the teaching-learning process, providing dynamic and innovative opportunities from active student participation. In this sense, the new Higher Education framework (2010) encourages teachers to integrate technology in the classroom, as it becomes clear in Horizon Report (2016), achieving a significant impact on education in the next three years [1]. To this end, teachers must not only use technological tools, but they should also familiarize themselves with the Technological Pedagogical Content Knowledge (TPACK) model to integrate technology with disciplinary, pedagogical and technological knowledge, offering more interaction between teachers and students [2].

Students are not mere spectators during their learning through the listening processes sitting in class, performing tasks and waiting for the teacher's answers. Students must actively participate on what they are learning, interact and transfer the contents and apply them to contextual situations. One of the teaching-learning processes that is gaining ground in the different educational levels is the B-Learning or mixed learning, defined as the combination of class work and online work with some 
control parameter over the path, time and rhythm to be followed, under the teacher's guidance, turning itself into a liable and proactive shared commitment integrating learning experiences. Within this rotation model, we find the "flipped classroom" hybrid sub-model developed in our research.

Most recent research works reveal the flipped classroom model has been widely used in several disciplines with positive results in university education [3-7]; trying to establish an alternative to traditional teaching through a learning that takes place when students acquire knowledge through experiences; being able to increase it with the use of tasks where students are active learners, participating in the analysis, synthesis and evaluation of contents, and, in turn, being passive learners by taking up information from the vision, hearing and reading of contents [8], and to remember, describe and apply, which would lead students to develop lower thinking skills, deepening knowledge and finally being able to develop superior thinking skills. Thus, the teacher needs to use his experience and his deep knowledge on the subject to be able to project and raise good tasks. These circumstances imply a transformation of the teaching function, because, in the traditional class, the teacher can be described as an "expert" who presents information in various formats waiting for the students to pay attention and understand the information, while, in the flipped classroom, the teacher has the role of a "counselor" who works with students to guide them through their individual and collective learning experiences [9].

The teacher designs intentional learning experiences and the student is responsible for exploring the materials, in their various formats, asynchronously provided to obtain basic knowledge before the teaching (Educause Learning Initiative, 2012), while the time in the classroom is dedicated to develop, with a greater deepening of the contents, by means of designing tasks for the integration of competences not just of knowledge, but helping them to be able to know to do and know to be through practical experiences. To develop this model, two phases are designed:

- Previous Learning phase: Students acquire basic knowledge of subjects by viewing the training materials provided by the instructor in various formats, such as online videos, podcasts, or text, audio, or visual diversified materials before the teaching.

- Classroom learning phase: Students have active student-centered learning activities in the classroom, such as interactive lectures, problem solving, case studies, lab experiments, role plays, collaborative design and creation, etc.

In short, it is necessary to introduce educational strategies that place the teacher as an activator role, maintaining an adequate teacher-student relationship, creating proposals for reciprocal teaching, establishing a frequent feedback, offering spaces for reflection and meta-cognition, and providing a clear message to be understood [10].

The literature review shows us the scarce studies with regards to the flipped classroom model in students of Educational Sciences, and, more particularly in Physical Education, unlike in Higher Education in other areas of knowledge, as shown by Zainuddin and Hajar [11]. They set out the different research areas in recent years, on the flipped classroom model, in which quantitative studies are slowly emerging, highlighting the works in Science, Technology, Engineering and Mathematics (STEM), Sociology, Humanities, Health, Business and English, without referencing studies on the field that concerns us, Physical Education, showing the need and importance of carrying out this type of work so good results reach other environments. However, more recently, two works have been found in Educational Sciences, by González-Gómez, Su, Airado and Cañada-Cañada [12], and Mingorance, Trujillo, Cáceres and Torres [13], the second one being developed with future Physical Education teachers.

Research focused on the flipped classroom effectiveness in Higher Education is extremely limited; however, some works found in the literature review show better academic performance, which results in students showing they can better understand the content, get higher scores on exams and improve their performance [4-6,12-15], although a limited improvement has also been found in other studies evaluating the results, where the flipped classroom group had higher exam scores compared to the traditional class group [16-18]. 
Focusing on the effectiveness and impact of the flipped classroom model on scores, we highlight some of the most recent works. Albert and Beatty [19] carried out a study comparing the performance among first year undergraduate students, in a module of introduction to management, evaluating the impact of a flipped classroom (2013) opposed to a master class (2012) on the scores obtained. To do this, they compared the traditional classroom taught by the same instructor using the same text and the same tests with the flipped classroom, and the results indicate that, for the scores for exam 1, the students of the traditional classroom obtained significantly lower results $(M=7.66$, $\mathrm{SD}=1.16)$ to students of the flipped classroom $(\mathrm{M}=7.92, \mathrm{SD}=1.51)$. For exam 2 , the students of the traditional classroom $(\mathrm{M}=7.37, \mathrm{SD}=1.3)$ obtained lower scores than students of the flipped classroom ( $\mathrm{M}=7.53, \mathrm{SD}=1.36)$, but the significance did not reach 0.05 , and, for exam 3 , the students of the master class $(\mathrm{M}=7.52, \mathrm{SD}=1.25)$ obtained significantly lower scores than students of the flipped classroom $(\mathrm{M}=7.7, \mathrm{SD}=1.42)$. There were no statistically significant differences between the two groups, but on average the scores increased by two points.

In the same way, Sahin, Cavlazoglu and Zeytuncu [15], in several mathematic sections, carried out a work with the aim of understanding the opinions of the university students in the flipped classroom courses with regards to the traditional classroom and to investigate how the flip affects their performance. The students achieved average scores in the test significantly higher in the flipped sections $(M=8.32, S D=1.36)$ than in the traditional classroom $(M=7.54, S D=1.69)$. In general, most students (83\%) stated that flipped learning prepared them better.

González-Gómez et al. [12] also evaluated the effects of the flipped classroom on the students' perception and performance in a scientific subject of the Degree of Primary Education in 2014/2015. The class was divided into two groups: the first followed a traditional methodology and the second one used the flipped classroom methodology. The results showed statistically significant differences in all evaluations with the flipped classroom students group, who obtained an average score of $6.23 \pm 1.81$ their highest score reached 9.8, while in the traditional classroom the average was $3.52 \pm 2.22$ and their highest score was 6.59 points. The percentage of students who successfully completed the course was $56.7 \%$ in the traditional classrooms, while the percentage of students who did it with the flipped methodology was $67.3 \%$. In general, students agreed that the flipped method provided them with the possibility of working autonomously and at home, making it possible to see the material again to catch up.

In addition, Mingorance et al. [13] carried out a research work with students of second year of Primary Education, in the field of Organization of educational centers (Physical Education), where the goal was to know whether with the flipped methodology ratings are best than the traditional methodology, which was confirmed and there were significant differences, highlighting among other issues the reduction of abandonment of the subject and as a result attendance, participation and interaction and the improvement of the final grades.

Finally, Borchardt and Bozer [20] carried out a work comparing the differences between a traditional course based on lectures and a micro-flipped classroom course to see if there were differences in three exams and in the general course scores, resulting increases in performance with the flipped method and that required at least one semester of execution to be significant.

However, not all research compared to traditional vs. flipped classroom in Higher Education turns out to be effective. In this sense, Blair, Maharaj and Primus [21], Lin, Zhu, Chen, Wang, Chen, Li, Li, Liu, Lian, Lu, Zou and Liu [22], McLaughlin, Griffin, Esserman, Dabidson, Glatt, Roth, Gharkhlonarehe and Mumper [23], Muzyk, Fuller, Jiroutek, O'Connor, Butler and Byron [24], and Ryan and Reid [25] provided results that do not show significant differences in students' performance through the exam scores in both formats, not improving the students' performance at the end of the course.

There are also different reports of improving classroom attendance and satisfaction $[13,14,22,26,27]$ participation and interaction among equals, students and teachers through a more significant shared communicative [3,4,28]. In turn, it is emphasized that the students' attendance, participation, interaction and feedback are manifested as important elements in the evaluation of the students' learning [13]. 


\section{Materials and Methods}

\subsection{Objectives}

The objectives of this study focused on analyzing whether there are significant differences in the academic performance and if it improves the attendance, depending on the methodology used in the global teaching-learning process, with the change of intervention paradigm, in which the main axis is student-centered.

\subsection{Research Design}

This research is empirical-analytical, of non-equivalent quasi-experimental groups (León and Montero, 2003). The data collection process was developed with a transversal design.

\subsection{Participants}

For the student selection, we worked with the students enrolled in the subjects of Organization of Educational Centers (Degree) of 2nd year Primary Education with honor in Physical Education, in the University of Granada. A simple random sampling was carried out among the entire student population, with 131 accepting and producing data sample.

\subsection{Data Collection Instruments and Procedure}

For the development of this research, the scores obtained at the end of the semester were considered, understanding this moment as the end of the intervention in both methodologies, avoiding strange variables in the work assumed along the semester. In the same way, throughout this period, the intervention was carried out by the same teacher, so that the teaching style and the classroom environment did not become strange variables. The experience took place in the subject of Organization, as part of the basic training of undergraduate students, developed in the second semester, in morning hours, for 15 weeks, with a weekly duration of three hours for the students, two hours of large group and few hours of small group, with two equated subgroups. The 2015-2016 control group students developed the teaching-learning process through a traditional methodology, in which the teacher presents the information during classes in multimedia format, carrying out various practical activities related to the topics, and waiting for students to pay attention and understand it.

The development of traditional teaching lessons occurred through exhibition classes of interactive contents between teachers and students, and, retroactively, in which the teacher took advantage of students' questions to redirect the subject toward the goals of the lecture in class. The development of traditional classes were structured in the following way: (a) Phase of introduction, in which the contents exposed in previous days were briefly reviewed, recalling the point left, hence being able to build new knowledge. In turn, what will be carried out in the new class arises with the aim of engaging students through the exposure to a problem or asking questions based on the content. (b) Phase of development, through the exhibition by the teacher in multimedia format (PowerPoint: text, video and images) with the inclusion of anecdotes and illustrative examples, trying to maintain a high level of attention. During the lecture, students listen, take notes, ask and make some brief comments on the process of interaction with the teacher, practical activities, through case studies, exhibitions of the students' works carried out and debates. (c) Phase of closing of the session using a synthesis of discussions, in which the emphasis is put on highlighting exposure through questions to students.

Students of the experimental group received their classes through a flipped classroom methodology during 2016/2017, in which students perform a previous work of development of the topics through videos, presentations, power point, readings and reflection on questions of control over the pre-class, while, during the class, the teacher works with them to guide them through their individual and collective learning experiences. 
The structure and development of the flipped classroom consisted of preparing and properly designing the intervention sessions, before the classroom, through online platform, and during the session, distributing the process in the following way:

(a) Phase of creating the contents to be taught in a multimedia format, using text, videos, audio recordings, and images of own development and search of contents and open network resources. To create the videos, Windows Movie was used. The presentations were made with PowerPoint that subsequently went to format video with E M PowerPoint video converter. Interactive questionnaires were carried out with the Moodle platform. The individual and collaborative activities were developed through Moodle, Hot Potatoes and Office.

(b) Phase of development of the learning environment through the Moodle platform, which can be accessed anytime, anywhere, out of the academic schedule. For each subject, a glossary of terms and an interactive lesson were developed, in which the student progressed by the same reading, viewing videos, images and answering the questions that were occurring as the lesson progressed by the lesson, to receive timely feedback form so students can understand and analyze the presented contents. Once the lesson is finished, students complement it by the reading of recommended articles and the viewing of videos related to those articles, later settling the forums to discuss ideas and begin to clear doubts, the appropriate activities and the self-assessment questionnaires to record the students' activity and to know the difficulties encountered by students before reaching the face to face classroom.

(c) Phase during the teaching, at the beginning, resolve the doubts students may have, hence, we analyze the registry's answers made by them in the lesson and in the questionnaires, turning occasionally to the videos proposed, by setting the time to participate, ask and understand what has been previously discussed. In this way, we begin the deepening of knowledge through the design of situations introduced through anecdotes, illustrative examples and problems that allow introducing the case, simulations in conflict organizational resolution, discussion groups, peer discussions and instruction and collaborative learning in small groups of 4-6 students to reflect on and evaluate the deepening of the content in the classroom.

(d) Phase at the end of the session, a synthesis of discussions is held, in which we place emphasis on outstanding issues developed in the classroom through questions to students for their level of understanding.

(e) Completion phase of the topic in its two parts, virtual and face-to-face, in which the students develop a final test of the lesson on the same platform with the timely feedback, to be ready to attend the subsequent exam.

\section{Analysis of Results}

The following variables were used in this study:

- Dependent variables (DV): performance in June and September.

- Independent Variables (IV):

- Factor 1: Course (2 levels, 1:2).

- Factor 2: Culture (3 levels, 1:3).

- Factor 3: Sex (2 levels, 1:2).

- Factor 4: Method (2 levels, 1:2).

- Metric Variable 1: Initial attendance.

- Metric Variable 2: Final attendance. 


\subsection{Descriptive Results Related to the Method and the Performance}

Before proceeding to make contrast hypothesis on each of the population parameters, we proceeded to graphically analyze the average performance scores for the months of June and September using the R "Ggplot2" package.

Figure 1 is a combination of a boxplot and a scatterplot, using Cartesian coordinates to show the values obtained in relation to each research methodology. It has been used to compare visually the average scores of each one of the methodologies and analyze trend data.

We see that the average scores obtained with the "Method 2" (flipped methodology) ( $\mathrm{M}=13.55$, $\mathrm{SD}=5.74)$ are superior with respect to the "Method 1" $(\mathrm{M}=6.92, \mathrm{SD}=6.78)$, i.e., the average performance of students who followed the "Method 2" was better than those who followed Method 1 . In addition, there are points that could potentially be outliers. They will be evaluated more closely in the following sections.

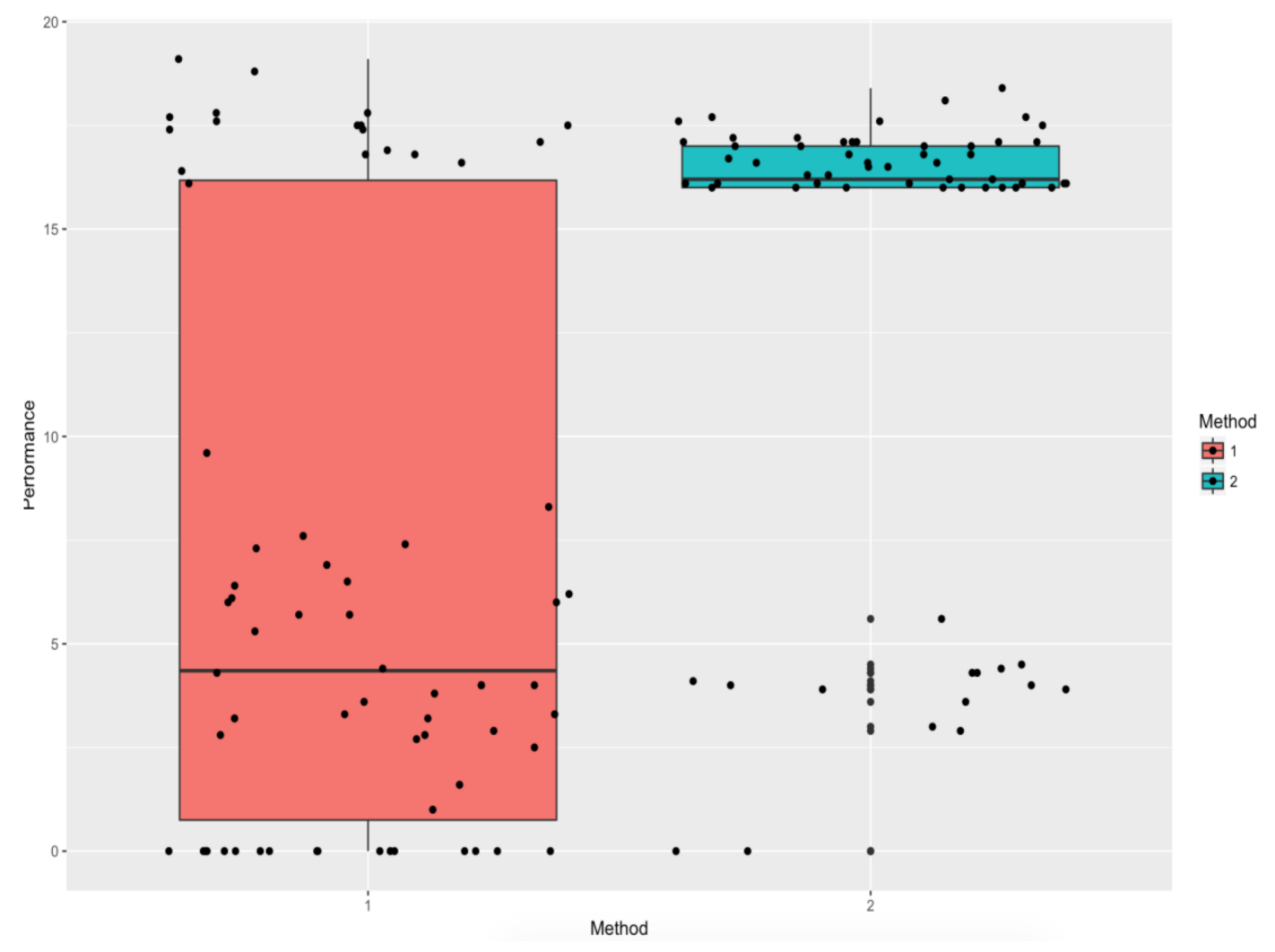

Figure 1. Average performance scores. * Method (Methodology): 1, traditional methodology; and 2, (flipped methodology).

\subsection{Evaluation of the Model Assumptions}

In this section, we evaluate the linearity assumption, presence/non-presence of atypical values, and the correlation degree between the study variables to determine the most appropriate statistical test (parametric/non-parametric/robust) to test the hypothesis.

\subsection{Evaluation of the Linearity, Atypical Values and Correlation between Metric Variables}

To evaluate the classic linearity assumption, presence of atypical values or outliers and the correlation between the different quantitative variables, the R "GGally" package was used, and more specifically the function "ggpairs". It contains templates for different plots to be combined into a plot matrix. 
Figure 2 shows the possible problems of linearity between the predictor variables of the study (scatter plots) to analyze the presence of outliers (boxplots) and the correlation between them (Pearson's correlation).

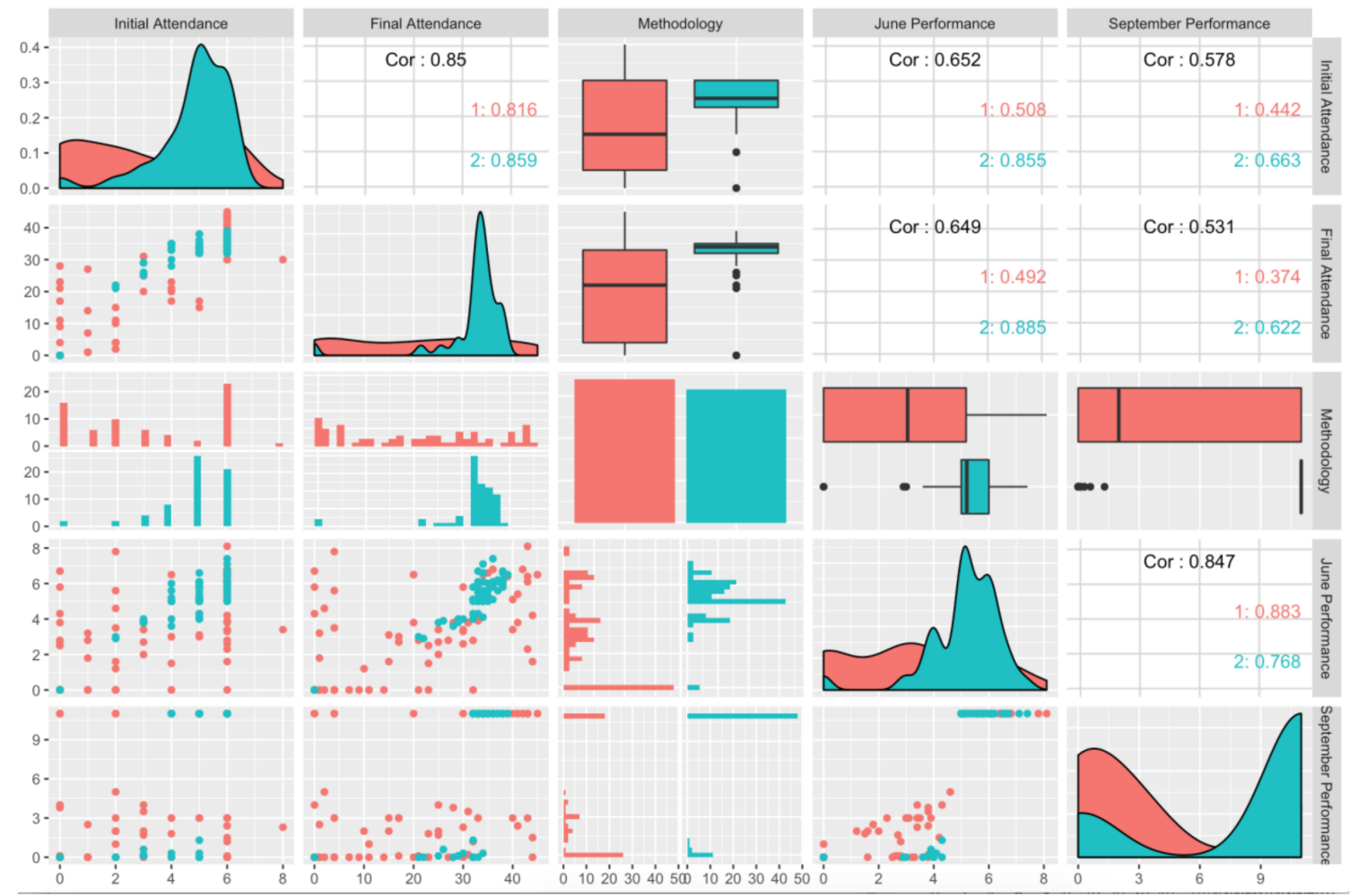

Figure 2. Linearity, outliers and correlations.

According to Figure 2, we can conclude that: (a) no linearity problems are observed between the different variables; (b) a strong correlation between "Method 2" and the performance in June and September exists, unlike for "Method 1"; and (c) a greater linear correlation between attendance in June and September exists with "Method 2" than with "Method 1", that is, this method could have improved the students' motivation.

Finally, the univariate normality assumption for the students' attendance to the different sessions and for the academic performance of the months of June and September was also assessed.

The results showed that neither the attendance data $(\mathrm{W}=0.85, p<0.05)$ nor those of performance $(\mathrm{W}=0.81, p<0.05)$ followed a normal distribution.

All previous results confirm that, because the univariate normality assumption and the presence of outliers were not fulfilled, it was considered necessary to carry out robust tests to increase the capacity to detect real effects in the treatment.

The parametric tests require the fulfillment of certain cases (usually normality and homoscedasticity), which do not comply with the data of the study. For this reason, we did not use them. In the same way, another possible alternative was the use of non-parametric tests since they are not based on any assumptions on data distribution. However, not all these previous tests are resistant in the presence of outliers, being the most appropriate robust evidence to carry out the analyses outlined then.

\subsection{Robust Test of Mean Comparison}

To carry out the robust test of mean comparison in the students' academic performance in the months of June and September, the YuenTTest function (Wilcox [29] and Yuen [30]) of the R DescTools 
package was used. This test is used with one or two samples, specifying these data in the function code, for trimmed means. The results showed there were significant differences in the academic performance, both in June $\left(\mathfrak{t}(-5.2)=50.38, p=3.514 \times 10^{-6}\right)$, and in September $\left(t(-5.8)=78.6, p=1.435 \times 10^{-7}\right)$ in terms of the method used.

\subsection{Multiple Linear Regression}

The multiple linear regression allows modeling the value of a variable according to one or more variables, through a monotonic linear function. That is, it assumes a change in the independent variable (IV) will result in a change in the dependent variable (DV), and the amount of the change in DV is constant for the entire range of the IV.

The multiple regression analysis is a supervised statistical technique to estimate the connection among the variables. We search then to define a simple mathematical function describing the development of one variable by applying one (simple regression) or more (multiple regression) other values. The application procedure is described next: First, before configuring the final model, the variable that we want to predict (dependent variable) needed to be set and we determined the connection with the rest of predictor variables (independent variables). Next, which of these independent variables contribute significantly to the model was determined. From a mathematical point of view, it can be represented as follows: In this study, we adjusted the linear model that included $X$ multiple predictor variables, using the multiple linear regression analysis: $y i=\beta 0+\beta 1 \times x i 1+\ldots$ $+\beta j \times x i j+\ldots+\beta p \times x i p+\varepsilon i$, where we have $p$ predictor variables $(j=2 \ldots p)$, and $n$ observations $(i=1 \ldots n)$. Yi value is the $i$ observation of the $Y$ response variable when the $X 1$ predictor variable equals $\mathrm{xi} 1$, the $\mathrm{X} 2$ variable is worth $\mathrm{xi} 2, \mathrm{Xj}$ is worth $\mathrm{xij}$, etc. The $\beta$ parameters are the regression coefficients. The $\beta 0$ intercept is the true mean value of $Y$ when all $X$ variables are worth zero.

The $\beta 1$ parameter is the (partial) slope or the change in $\mathrm{Y}$ per unit of change in $\mathrm{X} 1$, maintaining $\mathrm{X} 2, \mathrm{X}_{\mathbf{j}}$, etc. constant. Finally, $\varepsilon \mathrm{i}$ is the random or unexplained error associated with i observation.

In our case, it was interesting to build the multiple linear regression model only for the month of June to avoid strange variables that could have appeared in the month of September as a result of the vacation period. The coefficients of the model are shown in Table 1.

Table 1. Multiple linear regression model.

\begin{tabular}{ccccc}
\hline & Estimate & Std. Error & $\mathbf{t}$ Value & $\operatorname{Pr}(>|\mathbf{t}|)^{\mathbf{1}}$ \\
\hline (Intercept) & 0.94934 & 0.32870 & 2.888 & $0.00456^{* *}$ \\
Initial attendance & 0.36331 & 0.12222 & 2.973 & $0.00354^{* *}$ \\
Final attendance & 0.04376 & 0.02067 & 2.117 & $0.03621^{*}$ \\
Sex2 & 0.34325 & 0.30715 & 1.118 & 0.26589 \\
Method 2 & 0.78950 & 0.33619 & 2.348 & $0.02041^{*}$ \\
\hline
\end{tabular}

${ }^{1}$ Signif. codes: 0.001, “**”; 0.01, “*”; 0.05, ,."; 0.1, “ “. 1. Residual standard error: 1.602 on 126 degrees of freedom. Multiple R-squared: 0.4983, Adjusted R-squared: 0.4823. F-statistic: 31.28 on 4 and $126 \mathrm{DF}, p$-value: $<2.2 \times 10^{-16}$.

The resulting model is significant $(\mathrm{F}(4,126)=31.28, p<0.01)$ and the goodness of adjustment is moderate $($ R2aj $=0.4823)$, i.e., $48.23 \%$ of the variability of the scores of the academic performance in June is explained by the variables shown. To increase the R2aj, it would be advisable to incorporate future variables to improve the adjustment of the model.

The coefficients for the "initial attendance" and "final attendance" variables are significant, but the same is not true for the "sex" and "method" variables. The interpretation of the coefficients is then detailed.

The equation of the model is: June performance $=\beta 0.9434+$ Initial attendance $\times 0.36331+$ Final Attendance $\times 0.04376+$ Sex $2 \times 0.3433 \times$ Method $2 \times 0.7895$, where " $\beta 0$ " is the intercept (or constant) and " $\beta 1-\beta 4$ " represent the coefficient for the "Initial attendance", "Final attendance", "sex" and 
"method" variables, respectively. " $\beta 0$ " value indicates the change in response $(\mathrm{Y})$ due to a unit of change in predictors $(X)$.

Remembering the reference or basal category is "Method 1", the "Method 2" coefficient can be interpreted as the predicted difference between "Method 1" and "Method 2", that is, for each increase in one point of the scores of "Method 1" and "Method 2", the scores of "Method 2" further increase 0.079 points.

The "Method 2" coefficient can also be interpreted as the amount that is added to the predicted value when it is passed from one method to the other, that is, for the performance scores of the month of June with "Method 1" are equal to those of "Method 2", these have to increase by 0.079 points for each point.

Then, possible co-linearity problems in the predictor variables were evaluated with the "vif" function of the R "car" package. None of these variables (initial attendance, final attendance, sex and method) presented a VIF (Variance Inflation Factor) greater than 10, which indicates that co-linearity is not a problem in our data. The model was then reset by eliminating only those variables that are not significant (and in order according to the $p$-value if they were more than one variable). Our model was therefore defined as follows: June performance $=\beta 0.9434+$ Initial attendance $\times 0.36331+$ Final attendance $\times 0.04376+$ Method $2 \times 0.7895$.

\subsection{The Relative Importance of Predictors}

To evaluate the relative importance of predictors, i.e., the "initial attendance", "final attendance" and "Method 2" independent variables, the R "relaimpo" package was used (Figure 3).

\section{Relative importances for June Performance}

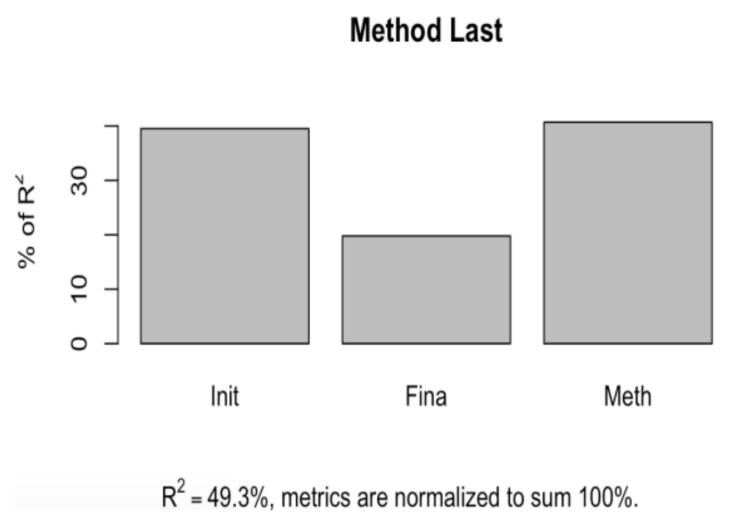

Figure 3. Relative importance of predictors. * Init (Initial attendance); * Fina (final attendance); * Meth (Methodology).

In the first column the "Initial attendance" variable appears, in the second "Final attendance" and in the third "Method 2". According to the Last Method, "Method 2" variable is the one that has the greatest importance in the linear regression configured model, i.e., it is the one that most contributes to the improvement of the students' academic performance in the month of June.

\section{Discussion}

The present moment urges the effective development of an educational model focused on learning assuming a great methodological and consequently cultural change, conforming a strategic plan with innovation proposals based on the emerging pedagogies, the consideration of good educational practices, the necessary teacher training, the social value, the development of the emotional competence and the ultimate consideration of shaping learning communities [31,32]. 
The use of the flipped classroom method stages a teaching-learning context where the average scores obtained have been better, in a linear way, than from a traditional methodological approach $[4,5,33]$ enabling critical meaningful training experiences, inserted in its environment and with social projection commitment, generating perspectives and possibilities on an ubiquitous, social, distributed and critical learning. All this must be developed from the dialogic value, promoting active participation, exercise of transformational and resilient leadership and picking collective intelligence.

According to the results obtained (especially innovative and significant in the field of Social Sciences and specifically in Physical Education) in this study, we have detected, in the same way, the strong correlation between the flipped classroom methodology and the performances in variable, sequenced and continuous periods, observing how motivational issues and consequently related to classroom attendance are binding and thus we have shown some of them [34]. The obsolescence of knowledge, increasingly accelerated, necessarily configures arguments in favor of the inclusion of new models (constructivist, social-constructivists, and humanists) and pedagogical structures (context, aims, and development) that promote an active and aware student through creativity and originality, promoting the development skills, where the evaluation processes are eminently competency-based (rubrics that consider linked standards and indicators), meaning new forms of organization (clover, network, virtual o ad hoc) and appearing new definitions of the tasks, giving a particular value to the learning to learn [35]. Thus, we emphasize the relevance of the students' active participation becomes a requirement, fully complying from his commitment and generating training spaces based on more meaningful learning and therefore transfer facilitators and practical application in diverse contexts (formal, not formal and informal). Thus, we suggest that the flipped classroom model be more considered by teachers because of its adaptation of student's own learning speed, permanent accessibility of the content, personalization, improvement of student performance, participation of community, responsibility and commitment to evaluation processes, etc.

We found that the performance (in June) is significantly determined by the initial assistance, the final attendance and by the method of flipped classroom, as regards to the multiple linear regression model. These results could be because this methodology empowers the ubiquity, autonomy, self-regulation, the empowerment of the strengthening of social cooperation, the resolution of cognitive problems, the ethical commitment and values and the functional learning are reflected in the use of this model [33].

It is interesting to note that month scores do not depended on the students' sex, in other words, this variable had no significant influence on them. The conclusions of this study are parallel with research works by Willians and Takaku [36] and Olajide [37], as no significant cash of the variable sex in the students' performance measured at the end of the academic year has been found.

Similarly, it was found that the predictor which had a greater weight on the scores obtained in the month of June was the flipped methodology, i.e., the students' performance in this month is explained more by the methodology to be followed than by other independent variables as the final and initial assistance.

In short, we can conclude that the improvement of academic performances, using the flipped classroom methodology are better compared to other groups that use traditional methodology, valuing relevant motivational issues and attendance and commitment related to those scores.

Therefore, the teaching-learning processes that use emergent and active pedagogies, such as the flipped classroom, offer openness and collaboration, democracy and commitment, being necessary its impulse by the enhancement of cognitive processes involved and especially the valuation of the improvement in the implicit performances. All this despite the possible difficulties that may limit their use, among which, we highlight the involvement degree, the necessary commitment and the demand level that especially determines in teacher and student planning alike.

Possible future research works focus on the consideration and study of Massive Open On-line Course MOOC resources, for example, as they facilitate the integration of the flipped classroom methodology, self-regulation perceptions and the improvement in the use of the flipped classroom, 
to develop the interactivity and reduce the high desertion of studies rates [38], and so analyze the conformation of effective personal learning environments, exploration of new techniques and strategies that encourage the students' interactive participation to increase their motivation degree, achievement of the classroom humanization, and effective development of emotions, among others. In addition, and from a statistical point of view, it is suggested to conduct multivariate classification techniques, which enable the identification those students with higher or lower scores to provide them quality feedback in line with the competencies or skills deployed in relation to each one of the methodologies followed.

We know that the flipped classroom methodology, as a reality, generates a more participatory, flexible, adaptive, effective and competency learning that definitively engages in a global project of methodological change that facilitates and certainly empowers people, groups and social movements. Perhaps, the increase of student's academic load and their optimal working mode to increase motivation and metacognitive skills should also be considered [39]. The precise combination of mobile technology, content and the students' willingness to learn are key aspects to create learning ecologies that go beyond the traditional formal and face to face context, integrating multiple virtual and interactive spaces [40] where the teacher becomes fundamental to form structures for critical and shared meaning.

Author Contributions: All authors participated in data collection. Francisco Javier Hinojo, Juan Manuel Trujillo and María Pilar Cáceres analysed the data. All authors contributed to data interpretation of statistical analysis. Juan Manuel Trujillo, Inmaculada Aznar and Ángel Custodio Mingorance wrote the paper with significant input from Francisco Javier Hinojo and María Pilar Cáceres. All authors read and approved the final manuscript.

Acknowledgments: This study was financed by PIBD 17-12 project entitled Flipped peer classroom, as an innovative teaching methodology for the training of future professionals in Education through semi-presence and collaborative learning environments in university. This project was endorsed by the National Agency for Quality Assessment and Accreditation (ANECA) and the Vice-Rectorate for Quality Assurance of the University of Granada (Spain).

Conflicts of Interest: The authors declare no conflict of interest.

\section{References}

1. Johnson, L.; Adams Becker, S.; Cummins, M.; Estrada, V.; Freeman, A.; Hall, C. NMC Horizon Report: 2016 Higher Education Edition; The New Media Consortium: Austin, TX, USA, 2016.

2. Harris, J.; Mishra, P.; Koehler, M. Teachers' Technological Pedagogical Content Knowledge and Learning Activity Types: Curriculum-based Technology Integration Reframed. J. Res. Technol. Educ. 2009, 41, $393-416$. [CrossRef]

3. Gilboy, M.B.; Heinerichs, S.; Pazzaglia, G. Enhancing student engagement using the flipped classroom. J. Nutr. Educ. Behav. 2015, 47, 109-114. [CrossRef] [PubMed]

4. Guy, R.; Marquis, G. The flipped classroom: A comparison of student performance using instructional videos and podcasts versus the lecture-based model of instruction. Issues Inf. Sci. Inf. Technol. 2016, 13, 1-13.

5. He, W.; Holton, A.; Farkas, G.; Warschauer, M. The effects of flipped iinstruction on out-of-class study time, exam performance, and student perceptions. Learn. Instruct. 2016, 45, 61-71. [CrossRef]

6. Heyborne, W.H.; Perrett, J.J. To Flip or not to flip? Analysis of a flipped classroom pedagogy in a general biology course. J. Coll. Sci. Teach. 2016, 45, 31-37. [CrossRef]

7. Liebert, C.; Lin, D.; Mazer, L.; Bereknyei, S.; Lau, J. Effectiveness of the surgery core clerkship flipped classroom: A prospective cohort trial. Am. J. Surg. 2016, 211, 451-457. [CrossRef] [PubMed]

8. Sams, A. Flip Your Students' Learning. Educ. Leadersh. 2013, 70, 16-20.

9. Bergmann, J.; Overmyer, J.; Wilie, B. The Flipped Class: What It Is and What It Is Not. The Daily Riff. 2012. Available online: http://www.thedailyriff.com/articles/the-flipped-class-conversation-689.php (accessed on 6 January 2018).

10. Fullan, M. The Principal: Three Keys to Maximizing Impact; Jossey-Bass: San Francisco, CA, USA, 2014.

11. Zainuddin, Z.; Hajar, S. Flipped Classroom Research and Trends from Different Fields of Study. Int. Rev. Res. Open Distrib. Learn. 2016, 17, 313-340. [CrossRef] 
12. González-Gómez, D.; Su, J.; Airado, D.; Cañada-Cañada, F. Performance and Perception in the Flipped Learning Model: An Initial Approach to Evaluate the Effectiveness of a New Teaching Methodology in a General Science Classroom. J. Sci. Educ. Technol. 2016, 25, 450-459. [CrossRef]

13. Mingorance, A.C.; Trujillo, J.M.; Cáceres, P.; Torres, C. Mejora del rendimiento académico a través de la metodología de aula invertida centrada en el aprendizaje activo del estudiante universitario de ciencias de la educación. J. Sport Health Res. 2017, 9, 129-136.

14. Koo, C.L.; Demps, E.L.; Farris, C.; Bowman, J.D.; Panahi, L.; Boyle, P. Impact of Flipped Classroom Design on Student Performance and Perceptions in a Pharmacotherapy Course. Am. J. Pharm. Educ. 2016, 80, 1-9. [CrossRef] [PubMed]

15. Sahin, A.; Cavlazoglu, B.; Zeytuncu, Y.E. Flipping a College Calculus Course: A Case Study. Educ. Technol. Soc. 2015, 18, 142-152.

16. Betihavas, V.; Bridgman, H.; Kornhaber, R.; Cross, M. The evidence for 'flipping out': A systematic review of the flipped classroom in nursing education. Nurse Educ. Today 2016, 38, 15-21. [CrossRef] [PubMed]

17. Geist, M.J.; Larimore, D.; Rawiszer, H.; Al Sager, A.W. Flipped versus traditional instruction and achievement in a baccalaureate nursing pharmacology course. Nurs. Educ. Perspect. 2015, 36, 114-115. [CrossRef] [PubMed]

18. Yacout, D.; Shosha, A. Nursing students' perceptions towards flipped classroom educational strategy. J. Am. Sci. 2016, 12, 62-75. [CrossRef]

19. Albert, M.; Beatty, B.J. Flipping the classroom applications to curriculum redesign for an introduction to management course: Impact on grades. J. Educ. Bus. 2014, 89, 419-424. [CrossRef]

20. Borchardt, J.; Bozer, A.H. Psychology course redesign: An interactive approach to learning in a micro-flipped classroom. Smart Learn. Environ. 2017, 4, 1-9. [CrossRef]

21. Blair, E.; Maharaj, C.; Primus, P. Performance and perception in the flipped classroom. Educ. Inf. Technol. 2016, 21, 1465-1482. [CrossRef]

22. Lin, Y.; Zhu, Y.; Chen, C.; Wang, W.; Chen, T.; Li, T.; Li, Y.; Liu, B.; Lian, Y.; Lu, L.; et al. Facing the challenges in ophthalmology clerkship teaching: Is flipped classroom the answer? PLoS ONE 2017, 12, e0174829. [CrossRef] [PubMed]

23. McLaughlin, J.C.; Griffin, L.M.; Esserman, D.A.; Dabidson, C.; Glatt, D.M.; Roth, M.T.; Gharkhlonarehe, N.; Mumper, R.J. Pharmacy student engagement, performance, and perception in a flipped satellite classroom. Am. J. Pharm. Educ. 2013, 77, 1-8. [CrossRef] [PubMed]

24. Muzyk, A.J.; Fuller, S.; Jiroutek, M.R.; O'Connor, C.; Butler, A.C.; May, D.B. Implementation of a flipped classroom model to teach psychopharmacotherapy to third-year Doctor of Pharmacy (PharmD) students. Pharm. Educ. 2015, 15, 44-53.

25. Ryan, M.D.; Reid, S.A. Impact of the Flipped Classroom on Student Performance and Retention: A Parallel Controlled Study in General Chemistry. J. Chem. Educ. 2016, 93, 13-23. [CrossRef]

26. Maarek, J.I.; Kay, B. Assessment of Performance and Student Feedback in the Flipped Classroom. In American Society For Engineering Education (ASEE); American Society for Engineering Education: Seattle, WA, USA, 2015. [CrossRef]

27. Clark, K.R. The Effects of the flipped model of instruction on student engagement and performance in the secondary mathematics classroom. J. Educ. Online 2015, 12, 91-115. [CrossRef]

28. Jungić, V.; Kaur, H.; Mulholland, J.; Xin, C. On Flipping the classroom in large first year calculus courses. Int. J. Math. Educ. Sci. Technol. 2015, 46, 508-520. [CrossRef]

29. Wilcox, R.R. Introduction to Robust Estimation and Hypothesis Testing; Academic Press: Cambridge, MA, USA, 2005.

30. Yuen, K.K. The two-sample trimmed $t$ for unequal population variances. Biometrika 1974, 61, $165-170$. [CrossRef]

31. Cortina Pérez, B.; Gallardo Vigil, M.A.; Jiménez Jiménez, M.A.; Trujillo Torres, J.M. Digital illiteracy: A challenge for 21st century teachers. Cultura y Educación 2014, 26, 231-264. [CrossRef]

32. Trujillo Torres, J.M.; Cáceres, M.P.; Aznar, I. Análisis del uso e integración de redes sociales colaborativas en comunidades de aprendizaje entre la Universidad de Granada (España) y la Universidad John Moores (Reino Unido). Revista Complutense de Educación 2015, 26, 289-311. [CrossRef] 
33. Chaves Barboza, E.; Trujillo Torres, J.M.; López-Núñez, J.A. Autorregulación del aprendizaje en entornos personales de aprendizaje en el Grado de Educación Primaria de la Universidad de Granada, España. Phys. Rev. 2015, 8, 63-76. [CrossRef]

34. Porcaro, P.A.; Jackson, D.E.; McLaughlin, P.M.; O’Malley, C.J. Curriculum Design of a Flipped Classroom to Enhance Haematology Learning. J. Sci. Educ. Technol. 2016, 25, 345-357. [CrossRef]

35. Trujillo, J.M.; Hinojo, F.J.; Aznar, I. Innovative and collaborative proposals e-learning 2.0 as a demand of the knowledge society. ESE Educ. Stud. J. 2011, 20, 141-159.

36. Wiliams, J.D.; Takaku, S. Help seeking, self-efficacy, and writing performance among college students. J. Writ. Res. 2011, 3, 1-18. [CrossRef]

37. Olajide, J.K. Effect of Integrated Approach on Polytechnic Student's Achievement in Essay Writing. J. Emerg. Trends Educ. Res. Policy Stud. 2013, 4, 917-924.

38. Stathaakarou, N.; Scully, M.L.; Kononowicz, A.A.; Henningsohn, L.; Zary, N.; McGrath, C. MOOC Learners' Engagement with Two Variants of Virtual Patients: A Randomised Trial. Educ. Sci. 2018, 8, 44. [CrossRef]

39. Stöhr, C.; Adawi, T. Flipped Classroom Research: From "Black Box" to "White Box" Evaluation. Educ. Sci. 2018, 8, 22. [CrossRef]

40. Rubia, B.; Guitert, M. Revolution in education: Computer support for collaborative learning. Comunicar 2014, 42, 10-14. [CrossRef]

(C) 2018 by the authors. Licensee MDPI, Basel, Switzerland. This article is an open access article distributed under the terms and conditions of the Creative Commons Attribution (CC BY) license (http:/ / creativecommons.org/licenses/by/4.0/). 